\title{
Arts-based research in Psychiatry: A way to the examination of the popular beliefs about mental disorders
}

\author{
Tabián Pavez ${ }^{1,2}$
}

T.PA Tirtual 2021. 29, th Thuropean Congress of Psychiatry 10-13 April 2021

Research about the depictions of psychiatry and mental disorders in popular culture has been scarce and often lacks systematized research strategies ${ }^{1}$. However, this tendency has changed in the last few years and it is now possible to find articles that investigate the social representations of mental illness through the analysis of the media, such as newspapers and social media ${ }^{2,3}$ and the products of popular culture, such as music, films, literature, and other artistic manifestations $\mathrm{s}^{4-11}$. The inclusion of the MeSH term 'Medicine in the Arts' in the database of the U.S. National Library of Medicine in 2018 is possibly indicative of the emerging relevance of this topic.

The study of the products of popular culture can give us information about common ideas present in the social imaginary regarding mental disease ${ }^{1}$. One advantage of this type of study is the public character of the data, which facilitates the accessibility, as well as the contrast and replication of findings. Also, the fact that artistic productions persist over time enables access to information that could not be gathered through other qualitative research designs. In this way, the products of popular culture could be seen as what I call 'cultural fossils', which can be 'traced back' to the historical time in which they were produced'. Therefore, artistic and cultural productions can offer a way of understanding prevalent ideas regarding mental illness and psychiatry in a specific time and place.

A systematic and replicable methodological framework is crucial for overcoming the purely anecdotal character of the research on social representations of mental illness in popular culture ${ }^{12}$ In this way, the use of content analysis, as a research method, is growing, particularly when it comes to literature analyzing representations of substance use disorders in popular culture (e.g. in songs or music videos) ${ }^{13-23}$. However, articles on substance abuse are mostly focused on the risk of exposure to harmful content among vulnerable audiences; rather than focusing on socia representations of mental illness more broadly. Moreover, substance abuse is not the only area of psychiatry in which these kinds of studies are useful. It is well known that the reproduction of stigmatizing depictions of mental disorders contributes to generating barriers to the access and acceptability of psychiatric treatments ${ }^{24,25}$. Hence, the importance of this research field is relevant to other areas of psychiatry, and not just substance use disorders. The identification of contents related to mental health in popular culture can be the first step in studying the potential impact of these depictions on the general population.

\section{References}

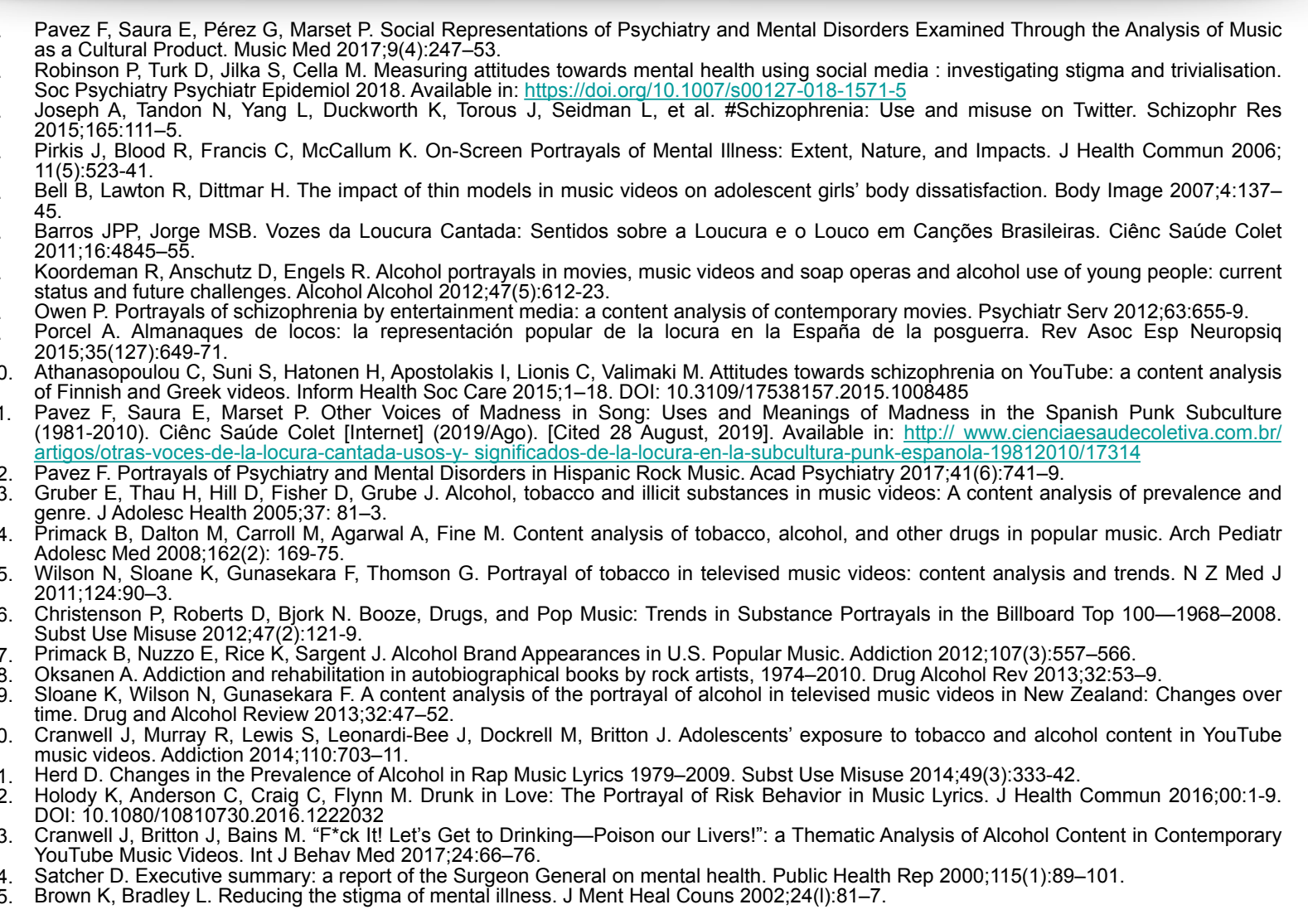

